\title{
CFD simulation of natural convection and heat transfer in a flat solar thermal collector with fins on the glazing - horizontal case
}

\author{
Laaraba Adel \\ ${ }^{I}$ Department of physics, University of BATNA. (05000) Batna, ALGERIA
}

laarabaadel@yahoo.fr

\begin{abstract}
This study is based on a CFD simulation of a flat horizontal solar thermal collector containing fins on its inner face of the glazing. The walls of the solar collector with insulation are considered adiabatic and the rest of the walls are at constant different temperatures. The principal objective of this work is to study the effects of the number of fins that changed from 0 to 30, as well as their length varied from 0 to 0.8 on the air flow and heat transfer characteristics. It has been observed that the heat transfer rate is strongly affected by the number of fins and the length of the fins. The obtained result showed that the increase of the fins reduces the heat loss by convection by $54 \%$.
\end{abstract}

Keywords: partitions number, fin, CFD, solar collector, natural convection

Received: 19/09/2018 - Accepted: 06/12/2018

\section{Introduction}

Algeria is a country that has a large capacity solar energy. Solar energy systems can work without problems in the sunny areas of southern Algeria [1]. These solar devices are based on solar rays and they are influenced by the intensity of solar radiation. Thus, the efficiency of solar devices changes with the seasons [2]. Transparent glazing plays a big role in solar devices such as solar collectors, solar distillers and solar heating. Double glazing for example increases the efficiency of the solar collector while it decreases the efficiency in the solar still $[3,4]$.

The use of the fins on the glazing has a great influence on the yield of the solar device [5]. The number of partitions on the glazing shows a reduction in heat loss [6]. The location of the fins on the inner face of the glazing and their length $\mathrm{Lp}$ in a divided rectangular cavity, have been studied in the case of natural convection coupled with radiation [7]. Still in the case of natural convection, the effect of the high location of the partition on the warm wall a heated square enclosure has been studied $[8,9]$. A study was based on the effect of thickness and thermal conductivity fins [10].

This simulation work is based on studying the influence of the number and length of fins on the performance of a solar thermal collector in a horizontal position.

\section{Problem description}

The geometry studied is a two-dimensional rectangular cavity containing fins glued to the inner glazing of the solar collector. Figure 1 shows a sketch of the problem under consideration, the dimensionless length of partitions Lp. It is considered that the solar collector is placed horizontally perpendicular to the field of gravity and the temperature gradient.

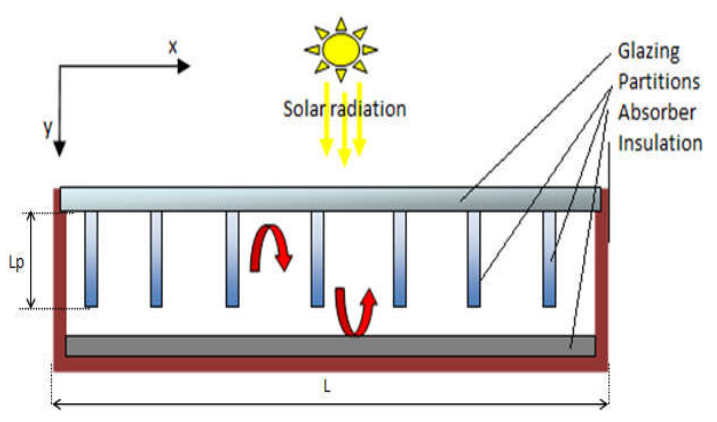

Figure 1. Schematic representation of the problem

\section{II.1 Boundary conditions}

The horizontal walls (glazing and absorber) are maintained at different temperatures, and the vertical walls are thermally insulated. That is,

-Horizontal Wall (absorber): $T=T_{H}$

-Horizontal Wall (glazing): $T=T_{C}$ 
- Vertical walls (insulation): $\frac{\partial T}{\partial x}=0$

No-slip conditions on all walls: $\mathrm{u}=\mathrm{v}=0$

The following assumptions are made to simplify the problem.

- The flow is steady, laminar and two-dimensional.

- The fluid is Newtonian and incompressible.

- Work induced by the viscous forces and pressure is negligible.

- The physical properties of the fluid (air) are considered constant except for its density which obeys the Boussines approximation in terms of buoyancy.

Therefore:

$$
\rho=\rho_{0}\left(1-\beta\left(T-T_{0}\right)\right)
$$

The power density dissipated is negligible.

\section{The mathematical formulation}

The governing equations considering the abovementioned assumptions are given below: Continuity equation

$$
\frac{\partial u}{\partial x}+\frac{\partial v}{\partial y}=0
$$

$\mathrm{X}$ - momentum equation

$u \frac{\partial u}{\partial x}+v \frac{\partial u}{\partial y}=-\frac{1}{\rho} \frac{\partial p}{\partial x}+v\left(\frac{\partial^{2} u}{\partial x^{2}}+\frac{\partial^{2} u}{\partial y^{2}}\right)$

$\mathrm{y}$-momentum equation

$$
u \frac{\partial v}{\partial x}+v \frac{\partial v}{\partial y}=-\frac{1}{\rho} \frac{\partial p}{\partial y}+v\left(\frac{\partial^{2} v}{\partial x^{2}}+\frac{\partial^{2} v}{\partial y^{2}}\right)+g \beta\left(T-T_{0}\right)
$$

Energy equation

$$
u \frac{\partial T}{\partial x}+v \frac{\partial T}{\partial y}=\alpha\left(\frac{\partial^{2} T}{\partial x^{2}}+\frac{\partial^{2} T}{\partial y^{2}}\right)
$$

The average Nusselt number which is employed to evaluate the effect of studied parameters on the heat transfer rate is calculated as:

$$
\overline{N u}=\frac{Q}{\lambda \Delta T}
$$

The governing equations with relevant boundary

conditions are solved by a commercial CFD code (ANSYS Fluent). SIMPLER algorithm is used to couple velocity and pressure. Convective terms in the governing equations are discretized by second order upwind difference scheme.

\section{III.1 Verification of the numerical procedure}

Based on the comparisons of average Nusselt number obtained in the present study and taken from the literature, which is given in Table 1 , one finds that the obtained results are similar and in agreement with those presented by different authors with a percentage of acceptable error. That is, the comparison presents an excellent concordance, which confirms that the procedure can be used for the further numerical simulation in this work.

Table1 Nusselt number comparison with the references values.

\begin{tabular}{|c|c|c|c|}
\hline Ra & Present Work & Ref. [11] & Ref. [12] \\
\hline $10^{3}$ & 1.116 & 1.118 & 1.118 \\
\hline $10^{5}$ & 4.549 & 4.545 & 4.523 \\
\hline
\end{tabular}

\section{Results and Discussions}

In this work the studied phenomenon is the natural convection in a partitioned rectangular cavity. The bottom wall (the absorber) is made of aluminum, and the outer wall (the glazing) is ordinary glass. The cavity (the gap of the thermal solar collector) contains the air. The objective is to study the influence of number and length of partitions on the heat transfer in the cavity. The simulations are performed for $\mathrm{Ra}=2.51 \times 10^{4}$ and $\mathrm{Pr}=0.71$. The results obtained are presented in the form of isotherms, streamlines and average Nusselt numbers.

To ensure that the accuracy of the results are independent from the mesh, calculations are conducted for several different structured meshes. The monitored parameter, average Nusselt number for different meshes is presented in Table 2.

Table 2 Average Nusselt number for different meshes.

\begin{tabular}{|c|l|l|l|l|}
\hline Mesh & $20 \times 400$ & $30 \times 600$ & $40 \times 800$ & $50 \times 1000$ \\
\hline$\overline{N u}$ & 73.16 & 74.87 & 75.34 & 75.40 \\
\hline
\end{tabular}

As seen in Table 2, the variation in average Nusselt is not significant between the meshes $40 \times 800$ and $50 \times 1000$. Thus, the former mesh is chosen to save computational time. The obtained results are presented below: 


\section{IV.1 Effect of partition length $L_{p}$}

\section{- The dynamic field}

The influence of partition length on the flow and heat transfer characteristics is discussed below. The partition length is varied from 0 to 0.8 while the number of partitions is kept constant at 5. Fig. 2, demonstrates the streamlines for $L p=0.0$ to 0.8 . As can be seen from the figure, for all the cases rolling cells are established in the enclosure. As the partition length increases, the fluid velocity decreases which consequently reduces flow circulation intensity.

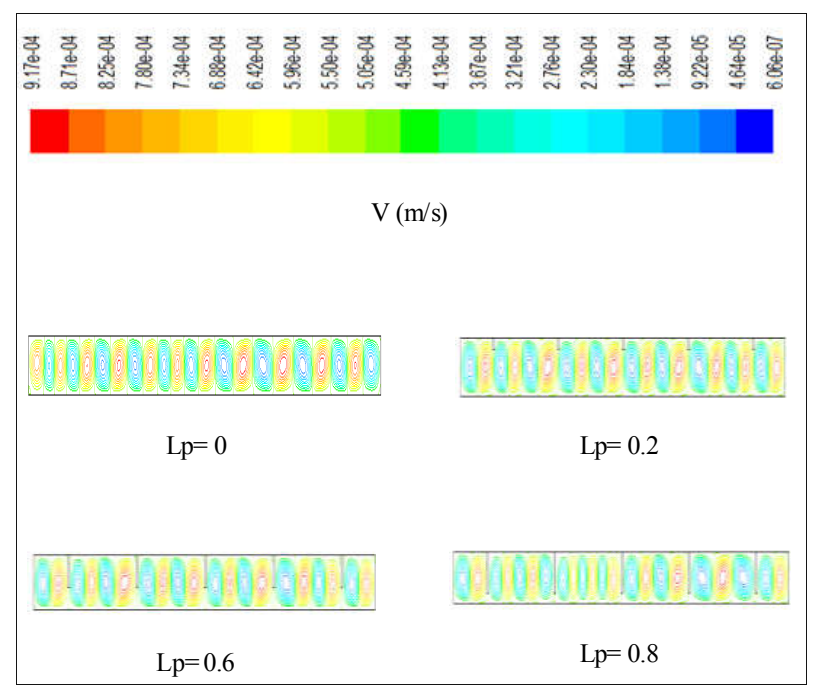

Figure 2. Streamlines for different partition length values $\left(\mathrm{Ra}=2.51 .10^{4}, \mathrm{~N}=5\right)$

\section{- The thermal field}

Figure 3, shows the isotherms for different values of $\mathrm{Lp}$ and 5 partitions. It note that there is a variation in the distribution of the temperatures in the air gap, when the increases of the length of partitions, which means the influence of $\mathrm{Lp}$ on the thermal transfer by natural convection in the air gap, therefore it is concluded that in the case horizontally the increase in the length of partitions cause a variation of thermal transfer by natural convection therefore a variation of thermal losses toward the outside. The movement of the fluid is forced to be close to the absorber.

The isotherms are presented in the figures below:

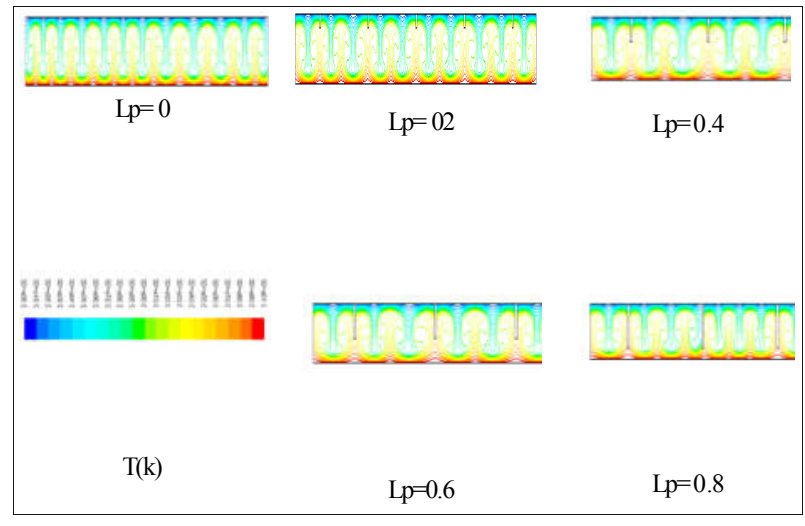

Figure 3. Isotherms for different values of $\mathrm{Lp}$ for $\mathrm{Ra}=2.51 .104, \mathrm{~N}=5$.

\section{- The average number Nusselt}

Figure 7 shows the variation in the number of average Nusselt depending on the length of partitions Lp, for a number of partitions equal to 5 . We note a gradual decrease in the value of the the Nusselt number when the length of partitions increases, which means a decrease of the thermal losses by natural convection to the outside $\mathrm{Ra}=2.51 \cdot 10^{4}, \mathrm{~N}=5$.

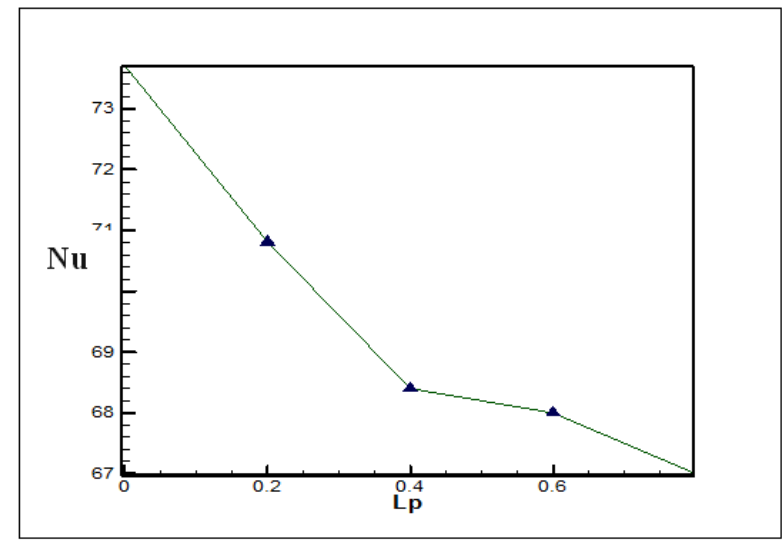

Figure 4. Variation in the number of average Nusselt for different values of Lp.

\section{IV.2 Effect of the number of partitions \\ - The dynamic field}

The dynamic field in the form of streamlines and velocity vectors:

Figure 5, shows the streamlines for different numbers of partitions for a length of 0.4 . We note that the movement of the air is close to the absorber below the partitions and form of waves when there is an increase in the number of partitions, which means an impediment of convective movements of the air in the air gap, this impediment cause a reduction of losses convective. It is observed that the reduction is at a maximum when $\mathrm{N}=30$. 


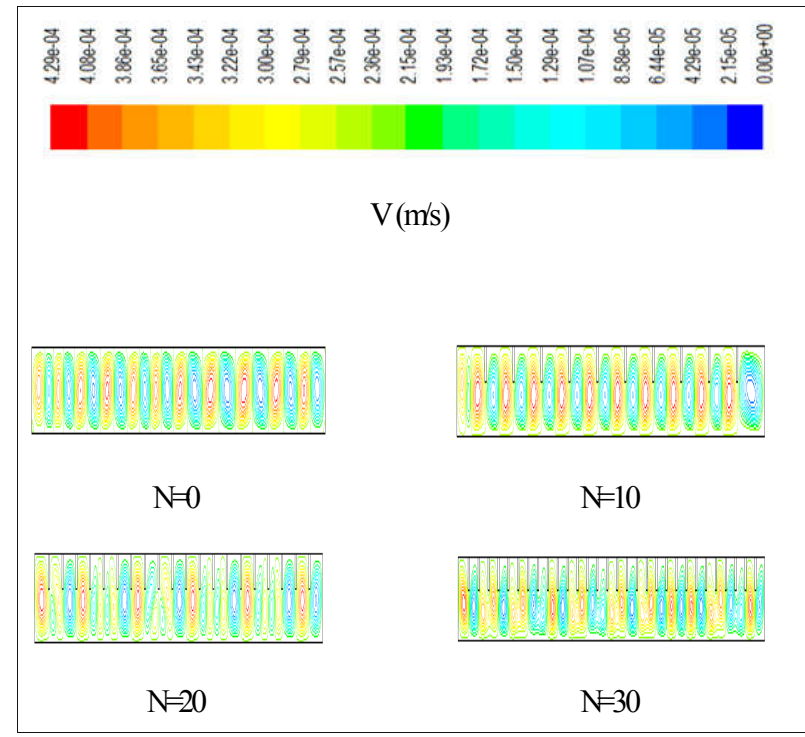

Figure.5. Streamlines and velocity vectors for different values of the number of partitions $\mathrm{N}$, for $R a=2.51 .10^{4}, \mathrm{Lp}=0.4$.

\section{- The thermal field}

The thermal field is presented in the form of the isotherms:

Figure 6, shows the isotherms for different numbers of partitions, in order to study the influence of the number of partitions. It has set their length to $\mathrm{Lp}=0.4$, and there has varied their number from 0 to 30 . We note in this figure that the increase in the number of partitions cause a variation in the distribution of the temperatures in the air gap of the solar collector, therefore an influence on the performance of the solar collector.

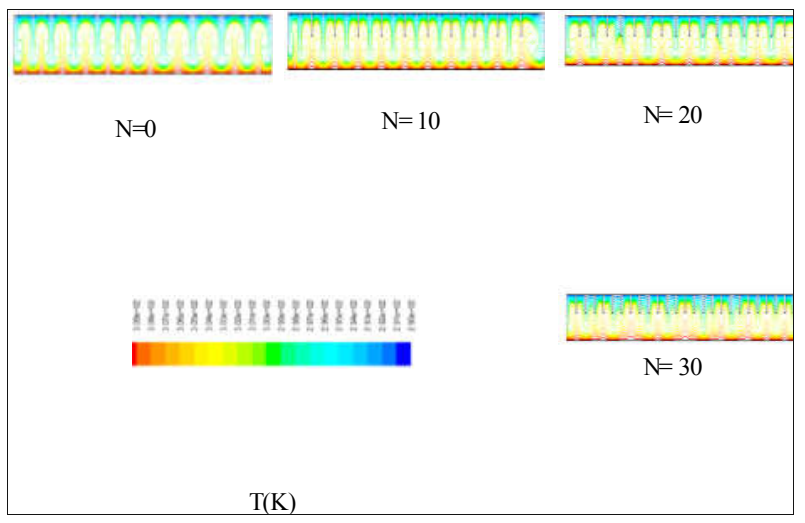

Figure.6. Isotherms for different values of the number of partitions $\mathrm{N}$ for $R a=2.51 .10^{4}, \mathrm{Lp}=0.4$.

\section{- The average Nusselt number}

Variation in the values of the average Nusselt number is represented in the figure below:

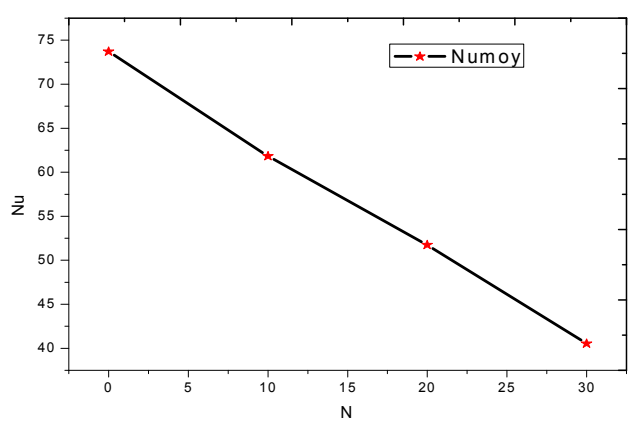

Figure.7. Variation in the number of average Nusselt for different numbers of partitions does for $\mathrm{Ra}=2.51 .10^{4}$.

Figure7 represents the variation in the number of average Nusselt with the number of partitions N. It note that the decrease in the values of this last when the number of partitions increases, it is concluded that the increase in $\mathrm{N}$ cause a minimization of convective losses.

\section{Conclusion}

In this study it indicate that the addition of partitions to the glazing wall can enhance the efficiency of the flat plat thermal solar collector with reduce of thermal losses by natural convection with $54 \%$. The effect of number and length of partitions is studied numerically. According to the previous results, it can be concluded that:

- The presence of partitions causes a decrease in the value of average Nusselt, therefore a minimization of thermal losses to the ambient.

- The increase in the length of the partitions cause a diminution the flow exchanged by convection, a maximum decrease for $\mathrm{L} p=0.8$.

- The increase in the number of partitions causes a decrease in the value of average Nusselt, and therefore a minimization of thermal losses toward the outside, by the impediment of convective movements of the air, a maximum decrease for $\mathrm{N}=30$.

- The increase in the number of partitions causes a lowering of the rollers to the bottom near the absorber, and dons an impediment of convective movements of the air.

\section{Nomenclature}

Gr: Grashof number

L: Length of the thermal collector (m).

Lp: dimensionless length of partitions

$\mathrm{N}$ : number of partitions

\section{Greek Symbols}

$\alpha$ : thermal

diffusivity $\left(\mathrm{m}^{2} / \mathrm{s}\right)$

$\lambda:$ thermal conductivity $(\mathrm{W} / \mathrm{m} . \mathrm{k})$ 
$\mathrm{Nu}$ : Nusselt number

Pr: Prandtl number

Ra: Rayleigh number

Re: Reynolds number

$\mathrm{Tp}$ : Temperature of absorber

(K)

$x, y$ : Cartesian coordinates $(\mathrm{m})$

$u, v$ : Velocity components

$(\mathrm{m} / \mathrm{s})$ $v$ : kinematic

viscosity $\left(\mathrm{m}^{2} / \mathrm{s}\right)$

$\beta$ : coefficient of

volume dilatation $\left(\mathrm{K}^{-1}\right)$

$\rho: \operatorname{density}\left(\mathrm{kg} / \mathrm{m}^{3}\right)$

$\rho_{0}$ : reference density

$\left(\mathrm{kg} / \mathrm{m}^{3}\right)$

\section{Acknowledgment}

I would like to thank Dr Müslüm Arıcı from Kocaeli University -Turkey, for his help and for his valuable remarks.

\section{References}

[1] S. Pahlavana, M. Jahangirib, A. Shamsabadic, A. Khechekhouche. Feasibility study of solar water heaters in Algeria, a review. Journal of Solar Energy Research. Vol 3, No 2, 2018, pp 135-146.

[2] A. Khechekhouche, A. Boukhari, Z. Driss, N. Benhissen. Seasonal effect on solar distillation in the El-Oued region of south-east Algeria. International Journal of Energetica. Vol 2. No 1. 2017, pp 42-45.

[3] H. Vettrivel, Palanivel Mathiazhagan. Comparison study of solar flat plate collector with single and double glazing systems. International Journal of Renewable Energy Research. Vol 7, No 1, 2017, pp 267-274.

[4] Abderrahmane Khechekhouche, Boubaker Benhaoua, Zied Driss. Solar distillation between a simple and doubleglazing. Recueil De Mécanique. Vol 2, No 2, 2017, pp 145-150.

[5] Adel Laaraba, Abderrahmane Khechekhouche. Numerical Simulation of Natural Convection in the Air Gap of a Vertical Flat Plat Thermal Solar Collector with Partitions Attached to Its Glazing. Indonesian Journal of Science \& Technology. Vol 3, No 2, 2018, pp .14-23.

[6] Ahmed. M. S. Amraqui, C. Abid. Combined Natural Convection and Surface Radiation in Solar Collector Equipped with Partitions. Applied Solar Energy. Vol 47, 2011, pp. 36-47.

[7] Bahlaoui and al. Numerical study of mixed convection coupled with radiation in a vented partitioned enclosure. International Scientific Journal for alternative energy and ecology. Vol 6, No 62, 2008.

[8] Paweena Khansila et al. numerical study of natural convection in porous square enclosure non-uniformly heated from the partitions. International Journal of Pure and Applied Mathematics. Vol. 96. No 2, 2014, pp. 2013228.

[9] A. Haghighi and K. Vafai. Optimal positioning of strips for heat transfer reduction within an enclosure. Numerical Heat Transfer. Vol. Part A, 66, 2014, pp. 17-40.

[10] Mehdi Khatamifara et al. Conjugate natural convection heat transfer in a partitioned differentially-heated square cavity. International Communications in Heat and Mass Transfer, 2016, pp. 12.
[11] S. Amraqui. Modeling of thermal transfers paired in a thermal solar collector cells with anti-losses. Doctorate thesis, 2009.

[12] G. De. Vahl. Davis. Natural convection of air in a square cavity: a bench mark numerical solution. Int. J. for Numerical Methods in fluids. Vol. 3, 1983, pp. 249-264. 